\title{
The Use of the Oregano (Origanum vulgare L.) Essential Oil and Hydrosol in Green Olive Fermentation
}

\author{
M. Musa Özcan ${ }^{1 *}$, Derya Arslan ${ }^{1}$ and Ali Osman Aydar ${ }^{2}$ \\ ${ }^{I}$ Department of Food Engineering; Faculty of Agriculture; Selçuk University; 42031 Konya, Turkey. ${ }^{2}$ Food \\ Engineer; Akhisar, Manisa, Turkey
}

\begin{abstract}
The effect of oregano the (Origanum vulgare L.) oil at the levels of 0.05, 0.1 and $0.3 \%$ and oregano hydrosol on the physicochemical, microbiological and sensory characteristics of the green olive (Edremit variety) fermentation was investigated. The initial $\mathrm{pH}$ of the oregano oil added samples were higher than the other treatments, which were above 5.8. The highest final acidity was observed in the hydrosol+brine combination (0.53\%). The initial LAB population on the first day of the fermentation was high in the diluted hydrosol (8.89 log $\left.\mathrm{cfu} \mathrm{ml}^{-1}\right)$ and control (8.47 $\log \left(\mathrm{cu} \mathrm{ml}^{-1}\right)$ samples. But a significant difference was not observed between the LAB counts of the treatments on the $40^{\text {th }}$ day of fermentation. The control and brine+oregano hydrosol samples had the highest sensory scores.
\end{abstract}

Key words: Green olive, fermentation, Origanum vulgare L., essential oil, hydrosol

\section{INTRODUCTION}

The table olives are one of the major agricultural commodities cultivated in the Mediterranean countries mainly in Spain, Italy and Greece and probably the most important fermented food in the Europe and worldwide (Tassou et al., 2002). As is the case with other fermented vegetable products (cucumbers, sauerkraut, etc.), the olive processing, despite its economic importance, has remained empirical and far from being controlled and modernized. Turkey is on the top rank out of fourty Mediterranean countries, but the olive fruits production shows fluctuations on a yearly basis. The oregano is indigenous to the sunny, sloping, hilly areas surrounding the Mediterranean. The leading suppliers are Turkey, Greece and Mexico. The taste is piquant, spicy, warm, pungent and slightly bitter. It is used commercially in the baked goods (pizzas, tomato sauces, condiments and salad dressing) (Farrell, 1990). The delay of the spoilage and improvement of the organoleptic qualities in the food manufacturing has a great importance. A number of the essential oils and several of their individual components exhibit antibacterial activity against the foodborne pathogens in vitro and to a lesser extent in the foods. The essential oils and their individual components are also used as food flavourings (Oosterhaven et al., 1995). In the foods, the essential oils can be put in order according to their antibacterial activity: oregano/ clove/ coriander/ cinnamon> thyme > mint> rosemary > mustard> cilantro/ sage (Burt, 2004).

The aim of this study was to evaluate the properties of the green olives fermented with the addition of the oregano oil and hydrosol with an attempt to determine the microbiological, physicochemical and sensory quality of the product.

*Author for correspondence 


\section{MATERIALS AND METHODS}

\section{Olive fruits}

The experiments were carried out with the green olive fruits of the "Edremit" variety harvested in September from Ayvalık, a region situated in the north west of Turkey. The olives were size graded to approximately $260-280$ fruits per $\mathrm{kg}$ and then washed simply with tap water to eliminate the dirt and undesirable risks of the spoilage.

\section{Brining procedure}

Then the fruits were placed in $2 l$ capacity screwcapped glass fermenters and filled with the freshly prepared brine (containing $10 \% \mathrm{w} / \mathrm{v} \mathrm{NaCl}$ ) and oregano oil with the levels of $0.05,0.1$ and $0.3 \%$ of the brine, oregano hydrosol (50\%) and brine $(50 \%)$ combination, oregano hydrosol $1 / 2$ diluted with the water and only brine as the control sample. After brining, the fermenters were kept at $25^{\circ} \mathrm{C}$. Duplicate samples were taken periodically for the microbiological and physicochemical analyses. The samples from the fermenter contents were taken under sterile conditions on the $1^{\text {st }}, 20^{\text {th }}$ and $40^{\text {th }}$ day of fermentation.

\section{Chemical analysis}

The brine samples were analyzed using a $\mathrm{pH}$ meter (Sentix 41 electrode, WTW-315i SET) for the $\mathrm{pH}$ and using a titration method with $0.1 \mathrm{~N} \mathrm{NaOH}$ in the presence of an indicator (phenolphthalein) for the free acidity. The $\mathrm{NaCl}$ content was determined according to Fernandez Diez et al. (1985).

\section{Microbiological analysis}

The lactic acid bacteria (LAB), total bacteria (TB), coliform bacteria (CB) and yeasts-molds (YM) were grown on the Rogosa agar, Plate Count agar, Violet Red Bile agar and Potato Dextrose agar (Merck, Germany), respectively (Tassou et al., 2002).

\section{Sensory analyses}

Acceptance sensory analyses were performed on the $40^{\text {th }}$ day of the fermentation according to Meilgaard et al. (1999) and Roberts and Kidd (2005). Twenty panelists were asked to taste each sample and to rate its overall acceptability using a 9-point hedonic scale with the scores ranging from 1:dislike extremely, to 5:neither like nor dislike and to 9:like extremely.

\section{Statistical analysis}

For the statistical analysis the ANOVA was performed on the two batches and the corresponding replicates using the Minitab for Windows (Release 7.1). Duncan test was used for the mean comparison.

\section{RESULTS AND DISCUSSION}

\section{Physicochemical changes}

The $\mathrm{pH}$ presented a decrease through the $40^{\text {th }}$ day of fermentation in all the cases (Figure 1). The initial $\mathrm{pH}$ of the oregano oil added samples were higher than the other treatments, which were above 5.8. But there were no significant differences between the samples on the $40^{\text {th }}$ day of fermentation ranging between 4.19-4.42. The control brine and hydrosol+brine combination showed the lowest $\mathrm{pH}$ values during the fermentation $(\mathrm{P}<0.01)$. The weak acidity on the first day of fermentation, ranging between 0.0097$0.0634 \%$, increased through the $40^{\text {th }}$ day in all the treatments. The highest final acidity was observed in the hydrosol+brine combination $(0.531 \%)$ $(\mathrm{P}<0.01)$. Tassou et al. (2002) determined the $\mathrm{pH}$ of black olives on the second month of the fermentation ranging from 3.6 to 4.8. Chammem et al. (2005), after the fermentation of green olives (Meski) with different alkali treatments and sodium chloride concentrations, reported the $\mathrm{pH}$ of samples between 4.22-4.76 and free acidity from $0.31-0.59 \%$ on the $26^{\text {th }}$ day of fermentation. These values were similar to the values obtained in the present study. The salt concentration decreased from 9.5 to $6.59-6.09 \%$ during the fermentation due to the osmosis of water in the fruits in the brine. The brix values of the oregano oil added brines were higher than the other samples. These values decreased from 8.5-9.0 to 7.1-7.8\% after 20 day. The brix values of $0.1 \%$ and $0.05 \%$ oregano oil added and diluted hydrosol slightly increased after 40 days fermentation. The brix values of the diluted hydrosol were low because of no salt content. 

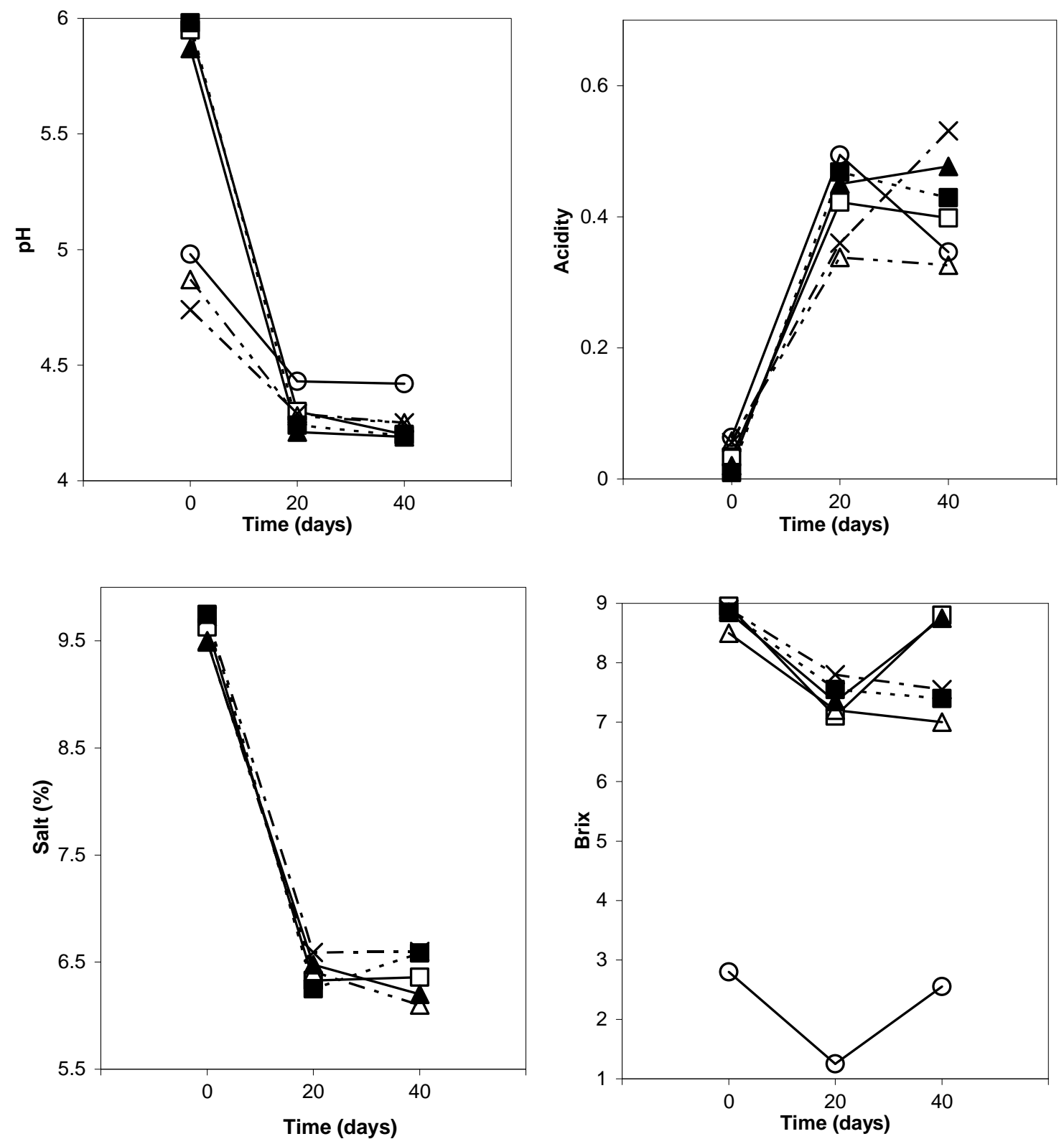

Figure 1 - Changes of $\mathrm{pH}$, titratable acidity (\%), salt (\%) and brix values during the fermentation of green

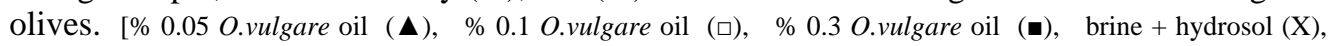
diluted hydrosol $(\mathrm{O})$, control $(\Delta)] *$ average of tree repetitions

\section{Microbial changes}

The microbial changes during the fermentation are given in Figure 2. The initial LAB population on the first day of the fermentation was high in the diluted hydrosol (8.89 $\log \mathrm{cfu} \mathrm{ml}^{-1}$ ) and control (8.47 $\log \mathrm{cfu} \mathrm{ml}^{-1}$ ) samples. The lowest initial LAB population was determined in $0.3 \%$ oregano oil added samples. The LAB counts decreased after 20 days but increased after 40 days of the fermentation. There was not a significant difference between the LAB counts of the treatments on the $40^{\text {th }}$ day of fermentation. Tassou et al. (2002) reported the LAB numbers were less than $3 \log \mathrm{cfu} \mathrm{g}^{-1}$ on the $40^{\text {th }}$ day of fermentation of 
the black olives in $8 \%$ brine. Leal-Sanchez et al. (2003) determined the total lactobacilli as $7 \mathrm{log}$ $\mathrm{cfu} \mathrm{ml^{-1 }}$ on the $40^{\text {th }}$ day of the fermentation of green olives. The LAB numbers were between 5.56-6.64 $\log \mathrm{cfu} \mathrm{ml}^{-1}$ in the present study. TB numbers were closer ranged between 7.30-8.70 log cfu $\mathrm{ml}^{-1}$. There were decreases in TB numbers after 20 day and then increases on the $40^{\text {th }}$ day of fermentation. The CB population on the first day of the fermentation was high, while the highest numbers were observed in the oregano oil added samples. The CB numbers decreased gradually during the fermentation. But, the $\mathrm{CB}$ number increased in diluted hydrosol between $20^{\text {th }}$ and $40^{\text {th }}$ days, which could probably be attributed to the no salt concentration. Also, the CB population was observed in $0.3 \%$ oregano oil added brine after 40 days of the fermentation which was probably due to the contamination.

\section{Acceptance sensory test}

The results of the sensory test are shown in Figure 3. The panelists did not detect any off-odour in any of the samples. The olives fermented in the brine as the control, and brine+oregano hydrosol combination were judged excellent with good acidic taste and colour. The $0.3 \%$ oregano oil brine was found to give a piquant flavour which was not acceptable in terms of overall eating quality. All of the samples were evaluated with the scores above 6 , except $0.3 \%$ oregano oil added brine.
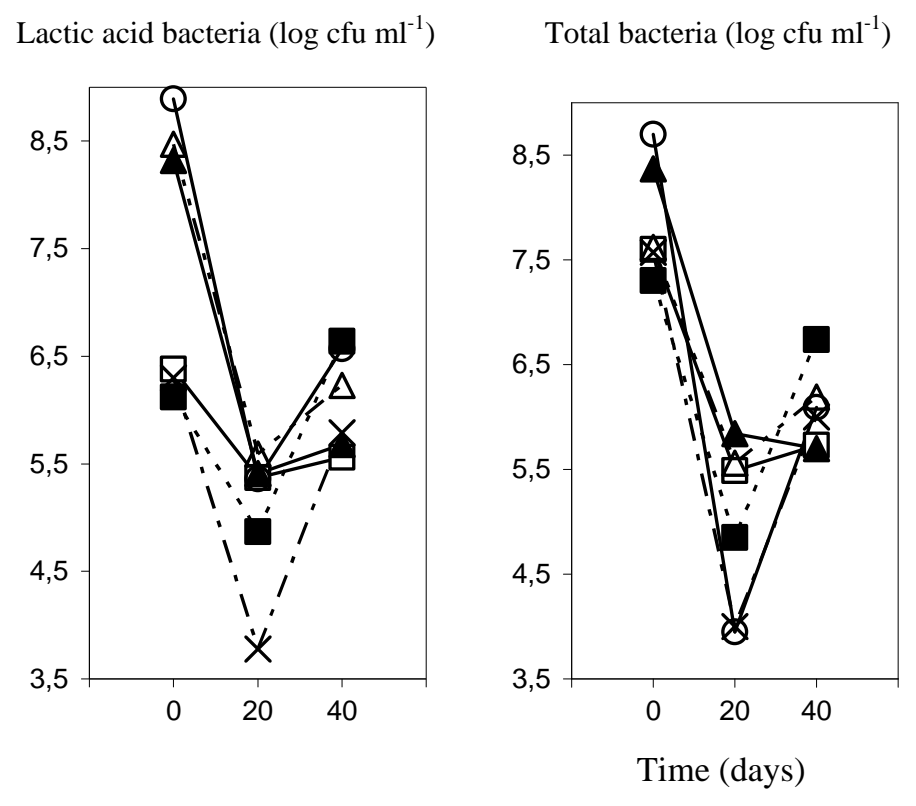

Coliform bacteria $\left(\log \mathrm{cfu} \mathrm{m}^{-1}\right)$

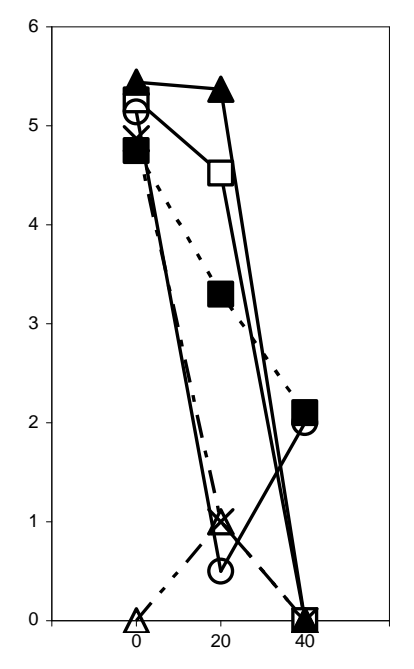

Figure 2 - Changes in lactic acid bacteria, total bacteria and coliform bacteria during the fermentation

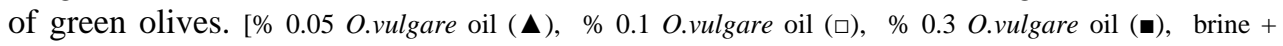
hydrosol $(\mathrm{X})$, diluted hydrosol $(\mathrm{O}), \quad$ control $(\Delta)] *$ average of tree repetitions 


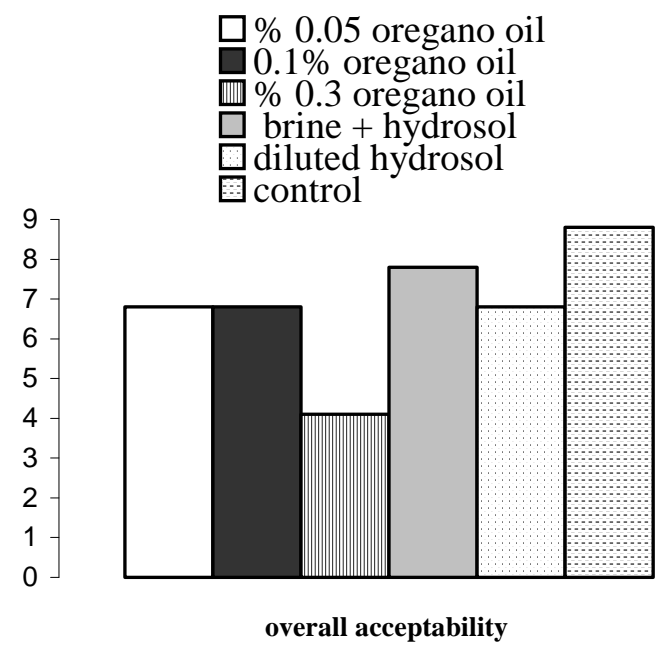

Figure 3 - Results of acceptance sensory test using a 9-point hedonic scale with the scores ranging from $1=$ dislike extremely, to $5=$ neither like nor dislike and to $9=$ like extremely

\section{CONCLUSIONS}

Oregano oil and hydrosol in the brine did not negatively affect the physicochemical and microbiological properties of the fermentation process. The levels of 0.05 and $0.1 \%$ oregano oil were acceptable, but $0.3 \%$ level left a piquant flavour to the product. The control and brine+oregano hydrosol combination had the highest sensory scores.

\section{REFERENCES}

Burt, S. (2004), Essential oils: Their antibacterial properties and potential applications in foods-a review. International Journal of Food Microbiology, 94, 223-253.

Chammem, N.; Kachouri, M.; Mejri, M.P.; Boudabous, A. and Hamdi, M. (2005), Combined effect of alkali pretreatment and sodium chloride addition on the olive fermentation process. Biosource Technology, 96, 1311-1316.

Farrell, K.T. (1990), Spices, Condiments and Seasonings, 2. ed. Van Nostrand Reinhold, New York.
Fernandez-Diez, M.J.; de Castro Ramos, R.; Garrido Fernandez, A.; Gonzalez Cancho, F.; Gonzalez Pellisso, F.; Nosti Vega, M.; Heredia Moreno, A.; Minguez Mosquera, M.I.; Rejano Navarro, L.; Duran Quintana, M.C.; Sanchez Roldan, F.; Garcia Garcia, P. and de Castro, A. (1985), In-Biotecnologia de la Aceitunas de Mesa, CSIC, Madrid, pp. 51-123.

Leal-Sanchez, M.V.; Ruiz-Barba, J.L.; Rejano, S.L.; Jimenez-Diaz, R. and Garrido, A. (2003), Fermentation profile and optimization of green olive fermentation using Lactobacillus plantarum LPCO10 as a starter culture. Food Microbiology, 20, 421-430.

Meilgaard, M.; Civille, G.V. and Carr, B.T. (1999). Sensory evaluation techniques, 3. ed. FL: CRC Press, Inc., Boca Raton.

Minitab (1991), Minitab Reference Manual (Release 7.1). Minitab Inc. State Coll., PA 16801, USA.

Oosterhaven, K.; Poolman, B. and Smid, E.J. (1995), Scarvone as a natural potato sprout inhibiting, fungistatic and bacteristatic compound. Industrial Crop Production, 4, 23-31.

Roberts, J.S. and Kidd, D.R. (2005), Lactic acid fermentation of onions. Lebensmittel-Wissen undTechnologie, 38, 185-190.

Tassou, C.C.; Panagou, E.Z. and Katsaboxakis, K.Z. (2002), Microbiological and physicochemical changes of naturally black olives fermented at different temperatures and $\mathrm{NaCl}$ levels in the brines. Food Microbiolology, 19, 605-615. 
PÁGINA

EM

BRANCO 